\title{
O LIVRO COMO CONSTRUÇÃO SIMBÓLICA: ENTRE A IDENTIDADE E AS TENSÕES
}

\author{
The book as symbolic construction: \\ Between identity and tensions \\ El libro como construcción simbólica: \\ Entre la identidad y las tensiones
}

André Carlos Moraes

Universidade Federal do Rio Grande do Sul

andre.moraes@uol.com.br

\section{Resumo}

Através de revisão bibliográfica e interpretação de dados empíricos, busca-se apontar elementos para ajudar a compreender o aspecto coercitivo sociocultural representado pelo livro impresso e pela leitura em uma comunidade de leitores, cotejando-se as teorias sobre construção simbólica com a observação de uma amostra de estudantes universitários de primeiro ano. Este esforço inicial de aproximação ao problema não buscou resultados conclusivos, mas a delimitação de um espaço embasado de pesquisa para futura investigação aprofundada.

Palavras-chave: Livro. Leitura. Práticas socioculturais.

\begin{abstract}
Through literature review and empirical data analysis, we seek to point out elements to recognize the cultural coercive aspect concerning the printed book and reading, within a community of readers. Theories about symbolic construction have been coupled with the observation of a sample of first-year college students. This initial effort did not seek conclusive results, but the delimitation of a space for future in-depth research.
\end{abstract}

Key words: Book. Reading. Cultural practices.

\section{Resumen}

A través de la revisión de la literatura y la interpretación de los datos empíricos, buscamos señalar elementos para ayudar a entender el aspecto coercitivo sociocultural representado por el libro impreso y la lectura en una comunidad de lectores, frente a las teorías sobre la construcción simbólica con la observación de una muestra de estudiantes universitarios de primer año. Este esfuerzo inicial no buscó resultados concluyentes, pero la delimitación de un espacio basado en investigación para futuras investigaciones en profundidad.

Palabras clave: Libro. Lectura. Prácticas socio-culturales. 


\section{INTRODUÇÃO}

Este artigo faz parte de uma pesquisa mais ampla que busca reunir elementos teóricos e empíricos para ajudar na compreensão do papel do livro impresso como processo comunicacional na cultura local contemporânea e sua diferenciação em relação a tecnologias como o livro eletrônico ou os meios audiovisuais. Especificamente, procura-se aqui empreender uma análise sobre o espaço deste suporte de informação a partir da observação da prática sociocultural de um grupo particular de leitores, uma amostra composta por estudantes universitários de primeiro ano. Através de revisão bibliográfica e com aporte de dados quantitativos e qualitativos oriundos de uma pesquisa inicial, são apresentados e discutidos indicativos a respeito de como o livro se constitui junto aos leitores simultaneamente como espaço de realização pessoal e social, identidade cultural e, mesmo, ponto em que se articulam tensões e coerções sociais.

A primeira seção contém conceitos e modelos teóricos tanto sobre o livro quanto sobre práticas culturais, ajudando a pinçar o sistema operacional que será utilizado como construto para a análise empírica. Em seguida, são apresentados dados do levantamento empírico. A partir daí, busca-se uma síntese, não na forma de conclusões mas no delineamento de um espaço interpretativo que pode ser utilizado como fundamento para problematizações futuras de pesquisa.

\section{MODELIZAÇÕES TEÓRICAS}

O presente trabalho é centrado no estudo de um objeto (o livro impresso) em função de seu uso sociocultural (sua apropriação pelos leitores). Este postulado deve ser compreendido em múltiplos níveis, compondo uma interseção de áreas. Um destes níveis, campo de origem do artigo, é a análise de um processo comunicacional. Isto considerando-se que a produção, circulação e consumo dos volumes impressos, como abordado a seguir na subseção 2.2, determina historicamente a emergência da imprensa, pioneira das formas de comunicação de massa. Mas há um outro nível de análise envolvido no objeto. Envelopando a própria área de Comunicação está a dimensão macroestrutural em que devem ser compreendidos os próprios fenômenos socioculturais dos quais as ações comunicativas fazem parte. Esta esfera mais ampla, na qual também é preciso problematizar o objeto, envolve conceitos de outras áreas, co- 
mo a Sociologia, História e Filosofia. A fim de progredir do geral para o particular, esta será a primeira porção do construto teórico apresentada, assunto da subseção a seguir.

\subsection{Práticas socioculturais}

Uma análise que envolva alguma forma de avaliação de dinâmicas sociais deve começar por apresentar um modelo funcional provindo da Sociologia, ainda que de forma breve. Aqui, o marco teórico inicial desta tarefa é a concepção de comunicação de massa como entendida por John B. Thompson (2002). Derivando conceitos de Karl Marx, o autor começa por estabelecer uma "análise da ideologia [...] primeiramente interessada com as maneiras como as formas simbólicas se entrecruzam com as relações de poder" (THOMPSON, 2002, p. 75). Para o tema do artigo, é parte importante desta definição o que Thompson chama de “construções simbólicas": "símbolos e 'slogans', costumes e tradições que mobilizam as pessoas ou prendem-nas, empurram-nas para a frente ou constrangem-nas" (THOMPSON, 2002, p. 58). É a partir deste conceito que o autor elabora sua visão de comunicação de massa, como "um conjunto de instituições relacionadas com a produção e com a distribuição massivas de bens simbólicos" (THOMPSON, 2002, p. 113). Ele observa que as "instituições e processos de comunicação de massa assumiram uma importância tão profunda nas sociedades modernas que nenhuma teoria da ideologia e da cultura moderna pode dar-se ao luxo de ignorá-las" (Idem).

Especialmente interessante na modelização de Thompson é sua relativização dos próprios conceitos. Fugindo das definições reducionistas ou simplistas, o autor chama atenção para a complexidade do fenômeno:

Os meios de comunicação de massa não são, simplesmente, um entre muitos
mecanismos para a inculcação da ideologia dominante; ao contrário, esses
meios são parcialmente constitutivos do próprio fórum em que as atividades
políticas acontecem nas sociedades modernas, o fórum dentro do qual e, até
certo ponto, com respeito ao qual os indivíduos agem e reagem ao exercer o
poder e ao responder ao exercício de poder de outros. (THOMPSON, 2002,
p.128)

Ou seja, para Thompson os meios de comunicação de massa em certa medida são parte do processo de construção simbólica que está envolvido na manutenção das relações de poder dentro da sociedade, mas também são, simultaneamente, espaço de conflito, a própria arena (o que ele chama de "fórum") onde se dão as atividades políticas de poder ou resistência. Esta maneira de ler o conceito do autor fundamenta um dos pressupostos teóricos do pre- 
sente trabalho, o entendimento de que um processo de comunicação possa ser espaço de tensão social.

Uma decorrência da definição de Thompson para os processos de comunicação de massa e sua análise é que ela necessariamente envolve o requisito de aporte empírico. Escreve o autor:

Se fenômenos simbólicos servem, ou não, para estabelecer e sustentar relações de dominação, é uma questão que pode ser respondida somente quando se examina a interação de sentido e poder em circunstâncias particulares somente ao examinar as maneiras como as formas simbólicas são empregadas, transmitidas e compreendidas por pessoas situadas em contextos sociais estruturados. (THOMPSON, 2002, p.76)

Com isso ele salienta a importância de não só mapear e identificar fenômenos simbólicos na esfera de sua constituição (no caso em pauta, isso equivaleria ao interior da comunicação de massa), mas examinar detidamente seu emprego em contextos sociais. Isso significa investigar os agentes sociais - observar os produtores e também os consumidores, no caso dos produtos da indústria cultural.

Este é o ponto em que se pode articular a modelização teórica de Thompson com projetos de pesquisa como o delineado por Michel de Certeau, que justamente chama a atenção para a utilidade de compreender as ações dos consumidores:

A presença e a circulação de uma representação (ensinada como o código da promoção sócio-econômica por pregadores, por educadores ou por vulgarizadores) não indicam de modo algum o que ela é para seus usuários. É ainda necessário analisar a sua manipulação pelos praticantes que não a fabricam. Só então é que se pode apreciar a diferença ou a semelhança entre a produção da imagem e a produção secundária que se esconde nos processos de sua utilização. (CERTEAU, 1998, p. 40)

Também o autor francês está preocupado em desvendar um jogo de tensões, quando contrapõe o que chama de "circulação de uma representação" à "sua manipulação pelos praticantes que não a fabricam”. Ele chega a explicitar esta proposição em termos que salientam o conflito:

[...] a cultura articula conflitos e volta e meia legitima, desloca ou controla a razão do mais forte. Ela se desenvolve no elemento de tensões, e muitas vezes de violências, a quem fornece equilíbrios simbólicos, contratos de compatibilidade e compromissos mais ou menos temporários. As táticas do consumo, engenhosidades do fraco para tirar partido do forte, vão desembocar então em uma politização das práticas cotidianas. (CERTEAU, 1998, p. 45)

Certeau é uma das referências em estudos sobre o livro ao propor justamente esta problematização das práticas do consumo em um contexto aplicado à leitura. Ele considera que 
“A leitura ficaria então situada na conjunção de uma estratificação social (das relações de classe) e de operações poéticas (construção do texto por seu praticante)" (CERTEAU, 1998, p.268). Esta visão foi sintetizada em forma axiomática em sua célebre afirmação de que "os leitores são viajantes; circulam em terras alheias, nômades caçando por conta própria através dos campos que não escreveram" (CERTEAU, 1998, p.270).

Conjugadas, estas observações de John B. Thompson e Michel de Certeau expressam uma preocupação de pesquisa que busca compreender articulações entre formas de representação social ou estruturas simbólicas, produtos culturais e consumidores, estes últimos capazes de suas próprias manipulações e táticas de resistência. Com Certeau, este espaço interpretativo se estende ao leitor e ao livro, assunto do presente artigo. Este objeto de estudo é definido na próxima subseção, que concluirá a modelização teórica.

\subsection{O Livro}

Antes de qualquer análise sobre um objeto de pesquisa é preciso defini-lo, ainda que rapidamente. Abaixo, uma descrição histórico-morfológica sobre o livro extraída de um texto didático da área de Comunicação:

Entre o século 1 a.C. e o século 6 d.C. o códex, ou manuscrito feito de páginas individuais encadernadas, começou a substituir o livro em forma de rolo e estabeleceu a forma moderna do livro. A publicação de livros continuou a evoluir, com impressão em blocos inventada na China em 600 d.C.; tipos móveis de liga de cobre inventados na Coreia em 1234; e a primeira prensa de impressão mecânica do mundo ocidental na Alemanha em 1455. A portabilidade dos livros e sua distribuição mais ampla após o desenvolvimento da impressão deram origem à primeira forma de comunicação de massa. Livros tiveram efeitos profundos na cultura e na sociedade disseminando novas ideias e construindo um corpo comum de conhecimento que pode ser compartilhado ao longo de gerações. ${ }^{1}$ (PAVLIK, 2010, p.105)

São pontos que convém destacar, nesta definição didática, o pioneirismo como "primeira forma de comunicação de massa" e os "efeitos profundos na cultura e na sociedade". O primeiro destes postulados justifica que se defenda a investigação do livro dentro da área de pesquisa em Comunicação. $\mathrm{O}$ segundo diz respeito à temática tratada aqui. O presente artigo não está centrado em aspectos tecnológicos ou sequer nos recursos informacionais do livro, que serão tratados em outras ocasiões. Interessa, neste momento, investigar justamente seu papel dentro da cultura.

\footnotetext{
${ }^{1}$ Original em inglês. Tradução do autor deste artigo.
} 
Estudos recentes utilizam a mesma tática de decompor, para fins de pesquisa, os elementos constituintes do livro, a fim de compreendê-lo em sua especificidade. A professora Leslie Howsam, da Universidade de Windsor, define da seguinte maneira uma obra que trata da multidisciplinaridade envolvida nos estudos do livro:

Old Books and New Histories busca ser uma orientação, uma espécie de guia de campo, para identificar e analisar os três maiores enfoques acadêmicos para estudos da história e cultura do livro. Estes enfoques ocorrem através dos estudos literários, bibliografia e história, disciplinas com problemáticas muito diferentes e algumas vezes conflitantes, que convergem sobre um fenômeno que é simultaneamente um texto escrito, um objeto material e uma transação cultural - o livro. ${ }^{2}$ (HOWSAM, 2006, p.VII)

É sob este ponto de vista que o livro é abordado aqui. Interessa discutir, justamente, como este preciso objeto material é imputado culturalmente de um papel social (o processo que Howsam chama de "transação cultural"), até mesmo de forma independente do conteúdo (o "texto escrito" citado pela autora).

Tanto educadores quanto pesquisadores assumem às vezes que a proximidade dos livros, mesmo fisicamente, seja em si mesma um agente de inclusão social. Em Sociologia da Cultura e das Práticas Culturais, Laurent Fleury menciona um estudo de Michèle Petit sobre o papel das bibliotecas públicas na criação da identidade de um grupo de jovens como cidadãos, “distinguindo igualmente espaço comum (no fundamento do indivíduo como ser particular) de espaço público (no fundamento do indivíduo como ser universal)" (FLEURY, 2009, p.86).

Uma leitura em maior profundidade da obra de Michèle Petit, para além dos trechos citados por Fleury, revela sua concepção do livro e da leitura como espaço de criação de identidade mas, também, de tensões sociais. Escreve ela:

Até uma época recente, a identidade se originava em larga medida de uma linhagem familiar e de pertencimento social, religioso, étnico. Após os ritos de passagem, reproduzia-se, em maior ou menor escala, a vida dos pais. E a leitura, quando se tinha acesso a ela, participava desta reprodução, como uma espécie de vestimenta - ainda que para alguns, pelo contrário, ela fosse um meio privilegiado pelo qual mudar o traçado do destino social. ${ }^{3}$ (PETIT, 2002, p.9-10)

A autora identifica historicamente nos livros e na leitura, assim, tanto uma construção de identidade quanto forma de fugir ao "traçado do destino social". Por outro lado, porém, ela também vê, ali, a possibilidade de uma imposição, principalmente sob o ponto de vista das novas gerações:

\footnotetext{
${ }^{2}$ Original em inglês. Tradução do autor deste artigo.

${ }^{3}$ Original em francês. Tradução do autor deste artigo.
} 
E a leitura, que foi para muitos adolescentes de gerações anteriores, e para uma parte dos de hoje, um gesto de recusa, de resistência, é percebida por vários outros como um gesto asséptico, de conformidade, de submissão; como algo que se confunde com o estudo, nos aspectos mais maçantes, e de que sempre se tem que prestar contas. Não mais abrir um livro, ou ao menos não mais ler as leituras recomendadas pela família ou pela escola, pode então lhes parecer como uma tomada de autonomia: se tanta gente resiste aos livros, é talvez porque se tente a todo custo empurrá-los goela abaixo. ${ }^{4}$ (PETIT, 2002, p.38)

Pode-se ponderar que as reflexões de Michèle Petit dizem respeito à leitura, não estando, portanto, necessariamente vinculadas ao objeto físico representado pelo livro impresso. $\mathrm{Na}$ classificação de Howsam dada mais acima, Petit estaria principalmente se referindo ao texto escrito, ou seja, o conteúdo. Mas é possível ir mais além e analisar a representação envolvida na própria fisicalidade do livro impresso, sua importância como objeto em si valorizado socialmente. É o que procura fazer o autor norte-americano Ted Striphas, autor de The Late Age of Print, um estudo sobre a importância do livro impresso na cultura atual. Striphas aponta, entre outras coisas, que a importância atribuída ao volume impresso (e ao seu conteúdo) é socialmente construída. Para isso, faz vários estudos de caso, utilizando como ponto de partida conceitos como o de Michel de Certeau de que o consumo é uma forma de produção paralela (STRIPHAS, 2011, p.179).

Uma das análises de Striphas é histórica, acompanhando a forma pela qual os editores norte-americanos se organizaram para despertar o consumo de livros, entre os anos 1920 e 1930. Ele cita o caso do relações-públicas Edward L. Bernays, que idealizou uma campanha para que figuras famosas atestassem a importância de possuir livros, ao mesmo tempo que procurou persuadir arquitetos e construtores a incluir prateleiras de livros nas casas novas a fim de estimular o consumo (STRIPHAS, 2011, p.27). Mas ele comenta que "em certa medida a construção de prateleiras de livros dizia menos respeito ao conteúdo dos livros que sobre a aparência de respeitabilidade e plenitude que a presença dos livros conferia aos proprietários de casas" ${ }^{\prime 5}$ (STRIPHAS, 2011, p.28), o que era curiosamente demonstrado por um dos hábitos da época, que era a venda de falsas lombadas de livros para decorar as prateleiras (Idem).

O mesmo Bernays, conta Striphas, lançou em 1931 uma outra campanha para "estigmatizar" (STRIPHAS, 2011, p.36) o empréstimo de livros, inclusive financiando uma campanha pública para que os cidadãos sugerissem um termo pejorativo para se referir ao "emprestador de livros, o sujeito que inferniza as vendas de livros e rouba os merecidos royalties dos

\footnotetext{
${ }^{4}$ Original em francês. Tradução do autor deste artigo.

${ }^{5}$ Original em inglês. Tradução do autor deste artigo.
} 
autores" (STRIPHAS, 2011. p.35). Tomadas em conjunto, estas campanhas dos anos 30 ilustram como a indústria livreira norte-americana procurava manter seu mercado conjugando estratégias ligadas tanto ao objeto físico quanto ao status social ligado a ele - em última análise um efeito de representação.

Neste ponto é necessária uma observação de cunho metodológico e mesmo epistemológico. Esta seção procurou trazer conceitos e modelizações teóricas. Na subseção dedicada aos construtos simbólicos e de representação, foram apresentadas proposições de John B. Thompson (2002) e Michel de Certeau (1994). Na subseção sobre o livro, foram trazidas reflexões e análises de Ted Striphas (2011) e Michèle Petit (2002). Todos estes autores, ainda que com aproximações diversas, compartilham entre si uma raiz epistemológica comum. Suas teorias são baseadas, ou pelo menos pressupõem, aporte empírico. Especificamente, envolvem estudos com consumidores ou leitores. É o que se depreende quando Thompson conclama a “examinar as maneiras como as formas simbólicas são empregadas, transmitidas e compreendidas por pessoas situadas em contextos sociais estruturados" (THOMPSON, 2002, p.76), ou quando Certeau, ao analisar a circulação de representações, aponta ser "necessário analisar a sua manipulação pelos praticantes que não a fabricam" (CERTEAU, 1998, p. 40). Neste sentido se justifica a próxima seção, que traz dados de uma pesquisa com leitores que podem ser relacionados à temática teórica apresentada até aqui.

\section{PESQUISA COM LEITORES}

Uma das finalidades do presente artigo é estender a análise dos dados obtidos através de um primeiro ciclo, inicial, da pesquisa. Esta seção utiliza resultados tabulados mas também dados brutos encontrados durante o trabalho de campo realizado para a dissertação de mestrado do autor, Entre livros e e-books: a apropriação de textos eletrônicos por estudantes ingressados na Universidade Federal do Rio Grande do Sul em 2011, com orientação de Ana Cláudia Gruszynski. Antes de entrar na análise, é útil apresentar resumidamente o trabalho.

O objetivo da pesquisa que efetuou o levantamento era observar os diversos usos de suporte paralelos ou complementares ao livro impresso junto a um público leitor específico. Foram escolhidos estudantes universitários de primeiro ano e o indicador primário adotado foi a lista de leituras obrigatórias para o vestibular. O corpus amostral foi composto por 263 estudantes de primeiro e segundo semestres de nove cursos: Medicina, Direito, Psicologia, Engenharia Civil, Biologia, Veterinária, Computação, Letras e Publicidade (um curso de cada 
Grande Área da Capes, selecionado a partir da maior densidade de candidatos por vaga no vestibular). Os alunos responderam a um questionário fechado que perguntava quantas obras da lista de 12 títulos obrigatórios haviam lido na íntegra ou parcialmente e quais suportes de leitura ou estudo haviam adotado para isso. Também foram agregados dados de observação direta colhidos por ocasião da aplicação do formulário. Foram realizadas quatro entrevistas semiestruturadas com respondentes da amostra, para fins de triangulação e consolidação dos resultados.

Um dos dados interessantes para o assunto em pauta diz respeito à última seção do questionário. Era uma pergunta aberta, para ser respondida com as próprias palavras dos estudantes: "Independente de estudo, trabalho ou faculdade, o que você lê?" O objetivo era observar a frequência com que seriam mencionados os diferentes suportes em estudo no trabalho. Um dos resultados inesperados foi que algumas respostas pareciam incorporar algum tipo de gradiente de valor, diferenciando categorias mais e menos valorizadas de acesso à informação. Exemplos no Quadro 1.

\begin{tabular}{|l|l|}
\hline \multicolumn{1}{|c|}{ RESPONDENTE* } & \multicolumn{1}{c|}{ RESPOSTA } \\
\hline VET9 & $\begin{array}{l}\text { Leio notícias (impressas ou na Internet) diariamente, revistas (sempre que possí- } \\
\text { vel) e livros em geral (cerca de dez por ano). }\end{array}$ \\
\hline VET15 & $\begin{array}{l}\text { Leio notícias na Internet, artigos científicos sobre veterinária e saúde. Literatura, } \\
\text { deixo mais para as férias que é quando leio romances ou terror (Edgar Allan Poe) } \\
\text { e policial (principalmente Sherlock Holmes, tenho a coleção toda). }\end{array}$ \\
\hline VET22 & livros, revistas, notícias (via Internet) \\
\hline LET21 & Livros de romance, poesia e teatro, revistas e periódicos na Internet \\
\hline MED2 & Livros de poesias, ficção, romance, jornais, revistas. \\
\hline MED13 & Jornal e Revistas / Romances [linhas diferentes] \\
\hline MED32 & Revistas, jornais, outros livros \\
\hline DIR1 & revistas, jornais e livros \\
\hline VET29 & Livros, revistas, jornais e artigos online que possuam um assunto de meu interesse \\
\hline
\end{tabular}

* Há um sistema de codificação para identificar os respondentes. As três primeiras letras correspondem ao nome do curso e os números são a ordem de tabulação do aluno

Quadro 1 - Respostas de alunos à pergunta "O que você lê?" com categorizações de valor Fonte: MORAES, 2012, p.194-196.

Pode-se observar como os alunos destacados no quadro acima utilizam alguma forma de gradiente ao indicar suas leituras. MED13 menciona em linhas diferentes duas categorias de leituras (em cima jornais e revistas, embaixo romances). VET9 oferece uma gradação baseada na frequência de leitura, com os livros ao final, mais espaçados. VET22 indica uma gradação discriminando suportes, com livros em primeiro lugar, revistas em seguida e por

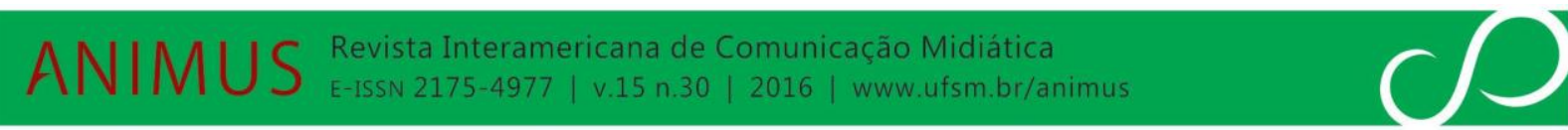


último as notícias on-line. Houve diversos tipos de resposta, mas aquelas destacadas no Quadro 1 se caracterizam por colocar os livros no cume de classificações. Eles encabeçam listas de importância decrescente (VET22, LET21, MED2, VET29) ou constam no final de listas de progressão crescente (VET9, VET15, MED13, MED32, DIR1).

Outro gênero de respostas trazia alguma forma de justificativa para o fato de que o aluno não lia. É possível observar esta tendência no Quadro 2. Uma das respostas recorrentes no Quadro 2 fazia menção à falta de tempo dos estudantes. MED18 disse só conseguir ler literatura nas férias; MED20 mencionou "alguns poucos livros"; DIR9 disse que "falta tempo" para ler, assim como DIR22; ENG16 disse que ainda não havia lido coisa alguma naquele ano; ENG8 fez uma estimativa do tempo que levava para ler os poucos livros que conseguia; LET3 indicou fazer leituras relacionadas à faculdade.

\begin{tabular}{|l|l|}
\hline \multicolumn{1}{|c|}{ RESPONDENTE } & \multicolumn{1}{c|}{ RESPOSTA } \\
\hline MED18 & $\begin{array}{l}\text { Principalmente artigos científicos e livros didáticos. Literatura apenas nas férias - leio } \\
\text { muitos livros em inglês para treinar... Procuro ler livros de diversas épocas/estilos }\end{array}$ \\
\hline MED20 & Alguns poucos livros de teoria política e alguns livros de romance. \\
\hline DIR9 & Atualmente só leio assunto relacionado ao meu curso - falta tempo \\
\hline DIR22 & ultimamente, nada; por falta de tempo. \\
\hline ENG2 & $\begin{array}{l}\text { Não tenho o hábito de ler muito, por isso quando vou ler algo, escolho aquilo que } \\
\text { mais me chama a atenção. }\end{array}$ \\
\hline ENG8 & na base de 1 livro sobre qualquer assunto a cada 2 anos e de vez em quando a Bíblia. \\
\hline ENG16 & $\begin{array}{l}\text { Nesse ano eu não li nada, mas eu gostava de ler livros baseados em histórias reais ou } \\
\text { romances. }\end{array}$ \\
\hline LET3 & $\begin{array}{l}\text { Os livros que leio são quase sempre relacionados à faculdade, como literatura } \\
\text { brasileira, literatura estrangeira e livros de linguística. }\end{array}$ \\
\hline
\end{tabular}

Quadro 2 - Respostas de alunos à pergunta “O que você lê?” com justificativas referentes a livros Fonte: MORAES, 2012, p.194-196.

Note-se que a redação da questão perguntava o que os estudantes liam fora do estudo ou trabalho. Era, intencionalmente, uma formulação aberta, destinada a observar as reações espontâneas. Muitos respondentes assinalaram diversos tipos de leitura, incluindo jornais, revistas e sites, como mostrado no Quadro 1. Aqueles que constam no Quadro 2, contudo, assumiram que era preciso de alguma forma prestar contas de sua relação com os livros. A reação é em parte uma decorrência do próprio processo de investigação. Sendo apresentada ao cabo de um questionário que tratava sobre livros, era natural que alguns entendessem que a pergunta se referia a este suporte de leitura. Ainda assim, esta não foi a interpretação adotada por todos os respondentes.

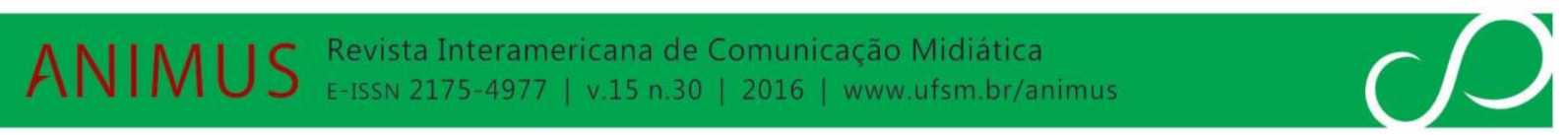


Pode-se interpretar os dados dos Quadros 1 e 2 em termos de representação simbólica. Os alunos que oferecem justificativas pelo fato de não lerem estão agindo de forma semelhante àqueles jovens descritos por Michèle Petit (2002). Eles assumem a leitura como algo "de que sempre se tem que prestar contas" (PETIT, 2002, p.38). Da mesma forma, a indicação de que o livro seja tratado com peso especial em relação aos demais tipos de informação (Quadro 1) e a própria justificativa pela sua não-leitura (Quadro 2) podem ser interpretadas em função dos "costumes e tradições que mobilizam as pessoas ou prendem-nas, empurram-nas para a frente ou constrangem-nas" (THOMPSON, 2002, p. 58).

Embora esta não seja a única interpretação possível, estes dados iniciais podem conter elementos indicativos de conformidade ou coerção social. Mas há outros dados no conjunto pesquisado que demonstram contrastes. Para entendê-los é preciso combinar resultados da observação. Na Tabela 1 constam as médias de leitura dos livros da lista de vestibular 2011 por curso. Eram 12 títulos. O curso com a maior média de leitura foi Medicina, com 8,9. O curso com a menor média foi Publicidade e Propaganda (PP), com 4,6. Comparando-se as médias de leitura com as densidades no vestibular, observa-se que as três maiores médias de leitura corresponderam na mesma ordem às três maiores densidades, Medicina, Direito e Psicologia. Mas a quarta maior densidade não seguiu o padrão. O curso de PP, apesar do índice de 14,7 candidatos por vaga no vestibular (maior que de outros cinco cursos), teve o menor índice de leitura.

Tabela 1 - Média de leitura dos livros da lista de vestibular por curso / densidade no vestibular

\begin{tabular}{|c|c|c|c|c|c|c|c|c|c|}
\hline Curso & MED & DIR & PSI & BIO & VET & COMP & ENG & LET & PP \\
\hline Média & 8,9 & 8,5 & 6,5 & 6,1 & 6 & 5,5 & 5,5 & 5,5 & 4,6 \\
\hline Densidade & 45,32 & 18,9 & 17,45 & 6,75 & 11 & 7,55 & 9,56 & 3,39 & 14,7 \\
\hline
\end{tabular}

Fonte: MORAES, 2012, p.79

Pode-se contrapor os dados de média de leitura e densidade no vestibular à leitura em livro. Na Tabela 2 consta a classificação de leitura em livro por curso. Ali são mostradas as percentagens de alunos que leram ao menos um título de forma integral utilizando o suporte do volume impresso. Nota-se uma semelhança parcial com a ordenação das médias de leitura, mas com algumas diferenças. Medicina e Direito seguem nas duas primeiras posições, PP na última.

Os números da Tabela 2 permitem observar um dos resultados da pesquisa visto também em outros indicadores que não serão apresentados aqui. Os dois cursos mais disputados, 
Medicina e Direito, que foram também aqueles com as maiores médias de leitura (Tabela 2), registraram maior vínculo dos alunos com o livro impresso. No caso da Medicina, observa-se pela Tabela 2 que todos os respondentes (100\%) realizaram pelo menos uma leitura nesta plataforma. Esta ligação era reforçada, por exemplo, pelo caso de alunos que leram todos os títulos da lista em papel, ocorrência mais frequente nestes cursos. Na Medicina e Direito, mais de um terço da amostra afirmou ter lido em livro entre 10 e 12 títulos. Uma aluna do Direito entrevistada pessoalmente comentou que lia os livros antes, depois fazia comparações com outros suportes e recursos de estudo, como filmes ou resumos.

Tabela 2 - Leitura integral de pelo menos um livro em papel

\begin{tabular}{|l|l|l|}
\hline Cursos & Leram íntegra & não leram íntegra \\
\hline MED & $100,00 \%$ & $0,00 \%$ \\
\hline DIR & $97,30 \%$ & $2,70 \%$ \\
\hline BIO & $96,15 \%$ & $3,85 \%$ \\
\hline COMP & $93,10 \%$ & $6,90 \%$ \\
\hline LET & $92,31 \%$ & $7,69 \%$ \\
\hline VET & $83,78 \%$ & $16,22 \%$ \\
\hline PSI & $80,95 \%$ & $19,05 \%$ \\
\hline ENG & $76,92 \%$ & $23,08 \%$ \\
\hline PP & $68,97 \%$ & $31,03 \%$ \\
\hline
\end{tabular}

Fonte: Adaptado de MORAES, 2012, p.105.

Para fazer o contraste, pode-se observar o caso da Publicidade e Propaganda. Nenhum dos alunos que integraram o corpus leu mais de 9 livros em papel. Mas a PP foi o terceiro curso com mais leitura em computador, o segundo em leitura de xerox e teve a percentagem mais alta de alunos que substituíram a leitura pelo ato de assistir a um filme baseado no livro. PP também empatou em primeiro lugar na amplitude de usos de suporte, ou seja, a quantidade de formas diferentes de acesso ao conteúdo dos títulos assinalada pelos estudantes. Um dos estudantes ouvidos pessoalmente durante a pesquisa era um estudante de Publicidade. Ele comentou não ter lido qualquer dos 12 títulos da lista de leituras obrigatórias, entretanto disse ter conseguido um alto escore de acertos na prova de Literatura do vestibular, após ter estudado os resumos. Mais radical é a posição de uma colega sua da PP, também ouvida, que disse não ter lido os livros “porque era muito fácil” fazer a prova sem lê-los.

As diferentes atitudes observadas junto aos estudantes no cumprimento das leituras obrigatórias do vestibular evocam a afirmação de John B. Thompson de que os meios de comunicação de massa são "o fórum dentro do qual e, até certo ponto, com respeito ao qual os indivíduos agem e reagem ao exercer o poder e ao responder ao exercício de poder de outros"

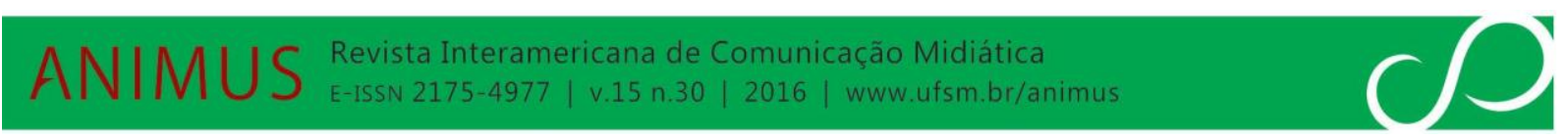


(THOMPSON, 2002, p.128). Pode-se entender, no universo reduzido do vestibular que é o exemplo em análise, que a Universidade representa o poder instituído, impondo uma lista de leituras obrigatórias. Alguns alunos dos cursos mais disputados e com maiores índices de leitura se alinharam a este poder, agiram "com respeito" a ele, nas palavras de Thompson. Especificamente, parecem ter aderido também com mais força ao suporte do livro impresso, justamente aquele que Ted Striphas associava à construção social de "aparência de respeitabilidade e plenitude" (STRIPHAS, 2011, p.28).

Mas os mesmos indicadores também apontam um conflito, na forma dos estudantes que não leram os títulos determinados pela Universidade, e até nas táticas usadas por eles para contornar estas exigências. Seria o ponto, nas palavras de Michel de Certeau, em que "a cultura articula conflitos" e "desloca ou controla a razão do mais forte" (CERTEAU, 1998, p. 45). Observa-se isto mais nitidamente nos casos do estudante de Publicidade que obteve boa nota na prova de Literatura do vestibular sem ter lido os livros e nos de seus colegas de curso que variaram suportes de acesso com este mesmo objetivo. $\mathrm{Na}$ atitude da estudante de PP que considerava muito fácil fazer a prova sem as leituras pode-se também notar um pouco do que Michèle Petit classifica como "gesto de recusa, de resistência" à "conformidade", "submissão" que alguns jovens associam ao ato de leitura (PETIT, 2002, p.38).

Não se buscou, aqui, destacar estratégias certas ou erradas de estudo, nem defender leitores ou não-leitores. O objetivo desta seção, e do próprio artigo, foi fazer um exercício empírico de interpretação com base em conceitos teóricos de representação, práticas socioculturais e construções simbólicas. Nas palavras de John B. Thompson, buscou-se "examinar as maneiras como as formas simbólicas são empregadas, transmitidas e compreendidas por pessoas situadas em contextos sociais estruturados" (THOMPSON, 2002, p.76).

\section{CONSIDERAÇÕES FINAIS}

Tanto a apresentação dos conceitos e autores quanto a exposição e análise dos dados neste artigo não tiveram pretensões conclusivas. Buscou-se apresentar modelos operacionais e delimitar um espaço coerente de interpretação e investigação, numa aferição de possibilidades embasadas de pesquisa. Esta proposição de entender os resultados em um âmbito prospectivo se impõe epistemologicamente e metodologicamente. O trabalho de campo que originou os dados estudados tinha outros pressupostos e outra finalidade, tendo sido planejado para comparar usos de suporte de leitura por parte de estudantes. O presente trabalho procurou dar con- 
ta das possibilidades de estender a observação e a interpretação a outros níveis envolvidos no objeto de estudo, a saber as representações simbólicas, usos socioculturais e tensões políticas oriundas do contato com o livro e a lista de leituras obrigatórias.

A compreensão da etapa epistemológica em que se encontra o trabalho desenvolvido aqui é um ponto que deve ser reforçado. Pesquisas como as dissertações de mestrado, as teses de doutoramento, estudos de maior ou menor abrangência costumam cumprir uma série de etapas metodológicas. Há uma consulta teórica inicial às fontes de referência da área; o planejamento técnico e metodológico; a observação; e a interpretação, que sintetiza todas estas instâncias. O presente artigo integra uma operação diferente, que envolve o retorno aos dados após uma segunda rodada de consulta teórica. Isso se deve ao fato de que a observação realizada no primeiro ciclo, aquele do mestrado, envolveu uma grande quantidade de informação (tanto qualitativa quanto quantitativa, como mencionado na seção anterior), cuja compreensão extrapolava o referencial teórico inicialmente adotado. O texto aqui apresentado resulta, então, de uma operação de cotejo e diálogo continuado entre teoria e realidade empírica. Justamente por isso, torna-se necessário entender quaisquer resultados como indicativos de um espaço interpretativo possível, sinalizadores de que uma próxima rodada de visitas de campo pode envolver a temática abordada aqui.

Estritamente do ponto de vista teórico, pode-se argumentar, a partir do exposto, da utilidade de uma linha de investigação que procure entender o livro não só como suporte de conteúdo mas como representação simbólica, um artefato imbuído de valor sociocultural que condiciona conformidades, tensões e conflitos em si mesmo. Compreender este componente de coerção e coesão social é mais uma tarefa dentro do esforço de pesquisa a longo prazo para desvendar o emaranhado de tecnologias, história e usos culturais representado pelo livro. Este mapeamento de construções simbólicas envolvidas no objeto de estudo, por sua vez, é necessário ao comparar o livro com os sucedâneos que se apresentam em uma sociedade crescentemente confrontada com novas tecnologias de informação, como os meios audiovisuais e os e-books. Ao decifrar fronteiras, interseções e hibridações entre estes suportes, torna-se necessário entender melhor seus componentes individuais ou compartilhados. Aqui, procurou-se contribuir com a prospecção de um desses níveis de descrição.

\section{REFERÊNCIAS}

CERTEAU, Michel de. A invenção do cotidiano. Petrópolis: Vozes, 1994 
FLEURY, Laurent. Sociologia da cultura: e das práticas culturais. São Paulo: Ed. Senac, 2009

HOWSAM, Leslie. Old books \& new histories: an orientation to studies in book and print culture. To-ronto: University of Toronto Press, 2006.

MORAES, André Carlos Moraes. Entre livros e e-books: a apropriação de textos eletrônicos por estu-dantes ingressados na Universidade Federal do Rio Grande do Sul em 2011. Porto Alegre: UFRGS, 2012. Dissertação (mestrado em Comunicação e Informação) - Programa de Pós-Graduação em Comunicação e Informação da Faculdade de Biblioteconomia e Comunicação, UFRGS, Porto Alegre, 2012.

PAVLIK, John Vernon. Converging media: a new introduction to mass communication. New York: Oxford University Press, 2010.

PETIT, Michèle.Éloge de la lecture: la construction de soi. Paris: Belin, 2002.

STRIPHAS, Ted. The late age of print: everyday book culture from consumerism to control. New York: Columbia University Press, 2011.

THOMPSON, John B. Ideologia e cultura moderna: teoria social crítica na era dos meios de comunica-ção demassa. Petrópolis: Vozes, 2002 